\title{
BMJ Open Demographic, occupational and societal risk exposures to physical injuries in a rural community in Western Kenya: a 12-week longitudinal study
}

\author{
Reagan Ngoge Chweya (D) , ${ }^{1}$ Susan Njoki Mambo, ${ }^{1}$ John Mwangi Gachohi (D) ${ }^{1,2}$
}

To cite: Chweya RN, Mambo SN, Gachohi JM. Demographic, occupational and societal risk exposures to physical injuries in a rural community in Western Kenya: a 12-week longitudinal study. BMJ Open 2021;11:e053161. doi:10.1136/ bmjopen-2021-053161

- Prepublication history and additional supplemental material for this paper are available online. To view these files, please visit the journal online (http://dx.doi.org/10.1136/ bmjopen-2021-053161)

Received 06 May 2021 Accepted 24 August 2021

\section{Check for updates}

(c) Author(s) (or their employer(s)) 2021. Re-use permitted under CC BY-NC. No commercial re-use. See rights and permissions. Published by BMJ.

${ }^{1}$ School of Public Health, Jomo Kenyatta University of Agriculture and Technology, Nairobi, Kenya

${ }^{2}$ Global Health Program Kenya, Washington State University,

Nairobi, Kenya

Correspondence to Reagan Ngoge Chweya; reaganngoge@gmail.com

\section{ABSTRACT}

Objective We studied factors associated with the weekly occurrence of physical injuries in a rural setting to determine injury-related burden and risk exposures. Design Prospective cohort study.

Setting Suna-West subcounty, Migori County, Western Kenya.

Participants 390 study participants (subjects) cluster sampled from 92 households, recruited and followed up for 12 weeks, between August and October 2019.

Methods We collected data weekly on occurrence of injuries, individual-level and household-level independent variables using a standard interviewer-administered questionnaire adapted from the WHO survey tool for injuries. Analyses related occurrence of injuries and independent variables using a multilevel Poisson regression model, adjusting for age and sex.

Outcome measures Quantifying injury-related burden and patterns by demographic, occupational and societal risk exposures.

Results We documented 44 injuries, coming from 38 subjects dwelling in 30 of the 92 study households. On average, each study subject and household experienced 1.2 and 1.5 episodes of injuries across the 12 study weeks. Open wounds and bruises were the most frequent injuries commonly reported among middle-aged (18-54 years) and young (5-17 years) subjects at 32.2 and 7.6 episodes per 1000-person week, respectively. The common cause of injuries among young, middle-aged and old subjects (>54 years) were falls, road accidents and person-related assault or being hit by an object, each at 15.2, 18.9, and 11.4 episodes per 1000-person week, respectively. Subjects not domesticating animals (incidence rate ratio (IRR) $=7.6,95 \% \mathrm{Cl} 1.4$ to 41.7 ) and those making a visit outside the local subcounty of residence (IRR=2.2, $95 \% \mathrm{Cl} 1.5$ to 3.1) were at higher risk of reporting injuries.

Conclusion We provide evidence of a higher burden of physical injuries associated with demographic, occupational and societal risk exposures with the most injuries resulting from falls. Further studies could better define granular characteristics constituting these factors.

\section{INTRODUCTION}

Globally, injuries impose an enormous public health burden and are projected to increase
Strengths and limitations of this study

- We evaluated temporal risks of injuries by demographic, occupational and societal exposures.

- We analytically controlled for the correlation of injury responses across time, between subjects and households.

- Self-reports of injuries are prone to bias but yielded reliable findings when collected within 7 days, with the weekly decrease suggesting response fatigue.

- Our multilevel analytical approach overcame the effect of loss to follow-up.

- Injuries may vary by time of year/season; however, the short study period meant a possibility of a fairly small number of injuries and not capturing all cases.

by $28 \%$ by $2030 .{ }^{1}$ Most injuries resulting from occupational risk exposures attributable to road traffic injury, violence or self-inflicted injury, and falls are among the leading causes of disease burden in sub-Saharan Africa. ${ }^{1-3}$ Although injury patterns remain to be well defined across different occupational settings, mobility-related injuries significantly increase disability-adjusted life years among individuals aged between 15 and 49 years calling for urgent interventions particularly in low-income countries. ${ }^{4}$

In most low-income countries, data on injuries are frequently obtained from hospital records. ${ }^{3}$ However, these records are collected under inadequate record-management systems; they are not population-wide representative in absence of injury-led surveillance systems and are widely inaccessible, contributing to underestimation of subnational injury-related burden. ${ }^{5}$ To address these gaps, self-reported data on injuries could be obtained to estimate the associated burden. ${ }^{5}$ Moreover, longitudinally collected self-reported data on injuries could causally identify and quantify risk exposures, as well as answer questions on the patterns 
and dynamics of acquiring injuries to better inform public health interventions. ${ }^{35}$

Past studies have identified demographic, occupational and societal risk exposures of injuries in Kenya. For instance, demographic changes have contributed to rural-urban migration, therefore increasing movements associated with rising road accidents, ${ }^{6}$ affecting persons of all age groups. ${ }^{7}$ However, resulting injuries from occupational exposures including road accidents and falls, among others, could cause disabilities that affect economically productive persons, leading to loss of wages and productivity, or impact education among adolescents. ${ }^{8}$ Additionally, societal risk exposures, including unsafe environments, poor enforcement of road safety regulations, inadequate road networks and poor access to quality healthcare interventions, contribute to the increasing number of injuries in rural settings. ${ }^{79}$ However, the current understanding of injury burden in Kenya is still limited by inadequate epidemiological data and surveillance systems. ${ }^{910}$ An alternative to address this challenge could be to longitudinally collect data on the occurrence of injuries in rural settings, ${ }^{10}$ quantify the burden, and assess patterns of injury by demographic, occupational and societal risk exposures. ${ }^{11}$

Here, we conducted a longitudinal study for 12 weeks aiming to achieve two linked aims: (1) to determine the longitudinal patterns of injuries and (2) to determine independent variables associated with physical injuries adjusting for study participants' age and sex.

\section{MATERIALS AND METHODS}

\section{Sample size determination}

The present study is part of a broader study looking into influenza-like, gastrointestinal illnesses and injuries in a rural setting. ${ }^{12}{ }^{13}$ In brief, 390 study subjects were cluster sampled from 92 households determined using a formula adapted from Multiple Indicator Cluster Survey Manual, $2005,{ }^{14}$ as follows:

$$
\frac{[4(0.5)(0.5)(1.5)(1.1)]}{\left[(0.12 * 0.5)^{2} * 5\right]}=92 \text { households }
$$

In the numerator, 4 denoted a factor to achieve the 95\% level of confidence; $(0.5)(0.5)$ denoted the binomial distribution in occurrence of injuries that would give a maximum variability in the target population ${ }^{15} ; 1.5$ denoted the design effect estimated as $1+$ (average household size-1) xintra-cluster correlation coefficients (ICC). We used an ICC of 0.125 to correspond with the ICC calculated for cluster sizes ranging between 2 and $50 .{ }^{16}$ A factor that raised the sample size by $10 \%$ to account for non-response was 1.1. In the denominator, $0.12 \times 0.5$ denoted the margin of error tolerated at the $95 \%$ confidence level, and 5 denoted the average household size in the study site.

\section{Study site and selection of households}

The study site and selection of the households are mentioned elsewhere. ${ }^{12}$ In brief, the study area was in
Suna-West subcounty in Migori County, Western Kenya, with Wasweta II ward, one of the four administrative wards within the Suna-West subcounty randomly selected as the study site. The estimated population size in the study site is 42244 , with a population density of about 450 persons/ $\mathrm{km}^{2} .{ }^{17}$ Additionally, the main economic activities in the area included agriculture and some commercial activities, including running small shops, mechanics, furniture works and tailoring, among others. To select representative households, we generated 92 random geographical points using QGIS V.3.6.1, each with Global Positioning System coordinates that we used to identify the study households. ${ }^{12}$ These coordinates were collected using the ODK Collect application ${ }^{18}$ on a smartphone. We tracked each of these points on the ground to identify the nearest household to each of these points and approached them for recruitment. Subsequently, we requested the household heads of these households on whether they could allow members of their households to participate in the study before obtaining written informed consent. A map of the household points was generated using R V.3.6.2 ${ }^{19}$ to visualise their spatial distribution and to easily identify the households during follow-up household visits. The Average Nearest-Neighbour Index determined the extent of the random distribution of the sampled households. ${ }^{20} 21$ This study was conducted between August and October 2019, where August marked the end of cold season, September a hot and dry season, and October the beginning of short rains.

\section{Study design, enrolment and longitudinal follow-up of subjects}

This study adopted a prospective cohort study design. A total of 390 subjects from the 92 randomly sampled households were recruited and followed up weekly for 12 weeks, excluding those aged below 5 years due to the unreliable reporting of their injuries. Subjects aged above 18 years provided their consent to participate in the study, while parental consent and subject assent were sought for those aged between 5 and 17 years. On every Friday of each week of follow-up, the household heads received a phone call from the principal author to inquire about any report of an injury within the study week. A report of an injury in a household member triggered a household visit to characterise the injury to the specific person injured using a standard questionnaire structured in a closed format by a trained research assistant. Injuries among subjects aged below the age of 18 years were characterised in presence of their parents or guardians. We conducted the questionnaire survey in the local 'Dholuo' language to ensure reliability and consistency of responses.

\section{Longitudinal data collection}

We had already obtained information on time-invariant factors relevant to sociodemographic, socioeconomic and household-level variables during the baseline survey. ${ }^{12}$ Briefly, these included independent variables considered as demographic, occupational, societal risks 
Table 1 Description of the time-invariant variables collected during the recruitment of study subjects

\begin{tabular}{lll}
\hline Factors & $\begin{array}{l}\text { Variable group } \\
\text { level }\end{array}$ & Factor levels \\
\hline Demographic & $\begin{array}{l}\text { Individual level } \\
\text { Household level }\end{array}$ & $\begin{array}{l}\text { Age in years, gender } \\
\text { Household sample size, income of the household head, active medical insurance, house } \\
\text { floor type, house roof type, house wall type, source of drinking water, mode of water } \\
\text { treatment, human waste destination, defecation location, trash disposal }\end{array}$ \\
Occupational & $\begin{array}{l}\text { Individual level } \\
\text { Household level }\end{array}$ & $\begin{array}{l}\text { Employment type, education level } \\
\text { Domesticated animals including cattle, sheep, goats, poultry, dogs and cats }\end{array}$ \\
\hline
\end{tabular}

broadly grouped at the individual and household levels. Demographic factors at the individual level included sex grouped into male and female subjects, and age categorised into those aged 5-17 years, 18-54 years, and $>54$ years hereinafter denoted simply as young, middle-aged and old subjects, respectively (table 1 ). Three regions arbitrarily defined the study area into the top, bottom left and bottom right according to their geographical positions (online supplemental figure 1S).

The weekly follow-up survey collected time-variant data consisting of the occurrence of injuries, causes, nature and severity, based on the WHO survey tool for injuries $^{22}$ (table 2). Time-variant risk factors include, among others, societal risks including the presence of visible stagnant water within household compounds due to rain and domesticating animals. In each week of study, we linked time-variant data to the time-invariant data collected at baseline for each subject. When a response was not obtained from any of the household heads during the follow-up weeks, a visit was made to the households to obtain the specific data within the week and to also motivate participant retention.

\section{Estimating the association between injuries and independent variables}

Adjusting for correlation of responses at the subject and household levels, we fitted generalised mixed effect models (GLMMs) with a Poisson error distribution and a $\log$ link function to examine the effect of the independent variables on injuries in two steps. First, we conducted a multilevel univariable analysis using a lessrestrictive level of significance of $p<0.1$ to identify single

\begin{tabular}{ll}
$\begin{array}{l}\text { Table } 2 \text { Description of the time-variant variables collected } \\
\text { weekly }(n=12)\end{array}$ \\
\hline $\begin{array}{l}\text { Variable } \\
\text { group level }\end{array}$ & Variable \\
\hline $\begin{array}{l}\text { Household } \\
\text { factors }\end{array}$ & $\begin{array}{l}\text { Household size, domestic animals, source } \\
\text { of drinking water, mode of water treatment, } \\
\text { human waste destination, defecation } \\
\text { location, trash disposal }\end{array}$ \\
$\begin{array}{l}\text { Individual } \\
\text { factors }\end{array}$ & $\begin{array}{l}\text { Visit outside the local subcounty, injuries by } \\
\text { severity, mechanisms, nature and intent }\end{array}$ \\
\hline $\begin{array}{l}\text { Environmental } \\
\text { factors }\end{array}$ & \begin{tabular}{l} 
Presence of stagnant water due to rain \\
\hline
\end{tabular} \\
\hline
\end{tabular}

significant risk factors. Second, we conducted a multilevel multivariable analysis to identify significant independent variables associated with injuries. All GLMMs adopted a maximum likelihood approach using Laplace approximation with flat covariance priors and normal fixed priors, with the household group and individual group IDs included as the random effects. To account for model uncertainty, the GLMMs were implemented in a Bayesian setting using the bglmer function in R software. ${ }^{19}{ }^{23}$ We examined time-invariant and time-variant risk factors described in tables 1 and 2, respectively, and included them as fixed effects in the model. In the multivariable analyses step, we forced age and gender in the models to account for their confounding characteristics. The final model was selected using the backward-stepwise selection process, whereby variables not contributing significantly to predicting the occurrence of injuries were eliminated based on low values of Akaike information criterion and Bayesian information criterion, signifying a better-fitted model.

We fitted a multilevel Poisson model based on our three-multilevel data structure organised as level 3: households, level 2: individual household member and level 1: repeated weekly measures. All analyses in this study were conducted using R V.3.6.2. ${ }^{19}$

\section{Patient and public involvement}

Patients and the public were not involved in the design, conduct of the study and determination of the outcome measures. Additionally, patients and the public were not involved in deciding the reporting tools, analysis and dissemination of study findings.

\section{RESULTS}

\section{Subject-level characteristics}

Descriptive characteristics of study subjects collected at recruitment are reported elsewhere. ${ }^{12}$ Briefly, of the 390 study subjects, $55 \%$ were female. The average age and SD of study subjects were 26.5 and 19.6 years, respectively, ranging from 5 to 83 years. About $53 \%$ were still schooling, while $84 \%$ had attained some primary education. Of the $47 \%$ non-schooling subjects, $46 \%$ and $1 \%$ engaged in informal and formal occupations, respectively.

\section{Enrolment and retention of subjects}

The enrolment and retention of the study subjects across the study weeks is reported elsewhere. ${ }^{12} 13$ Briefly, we 


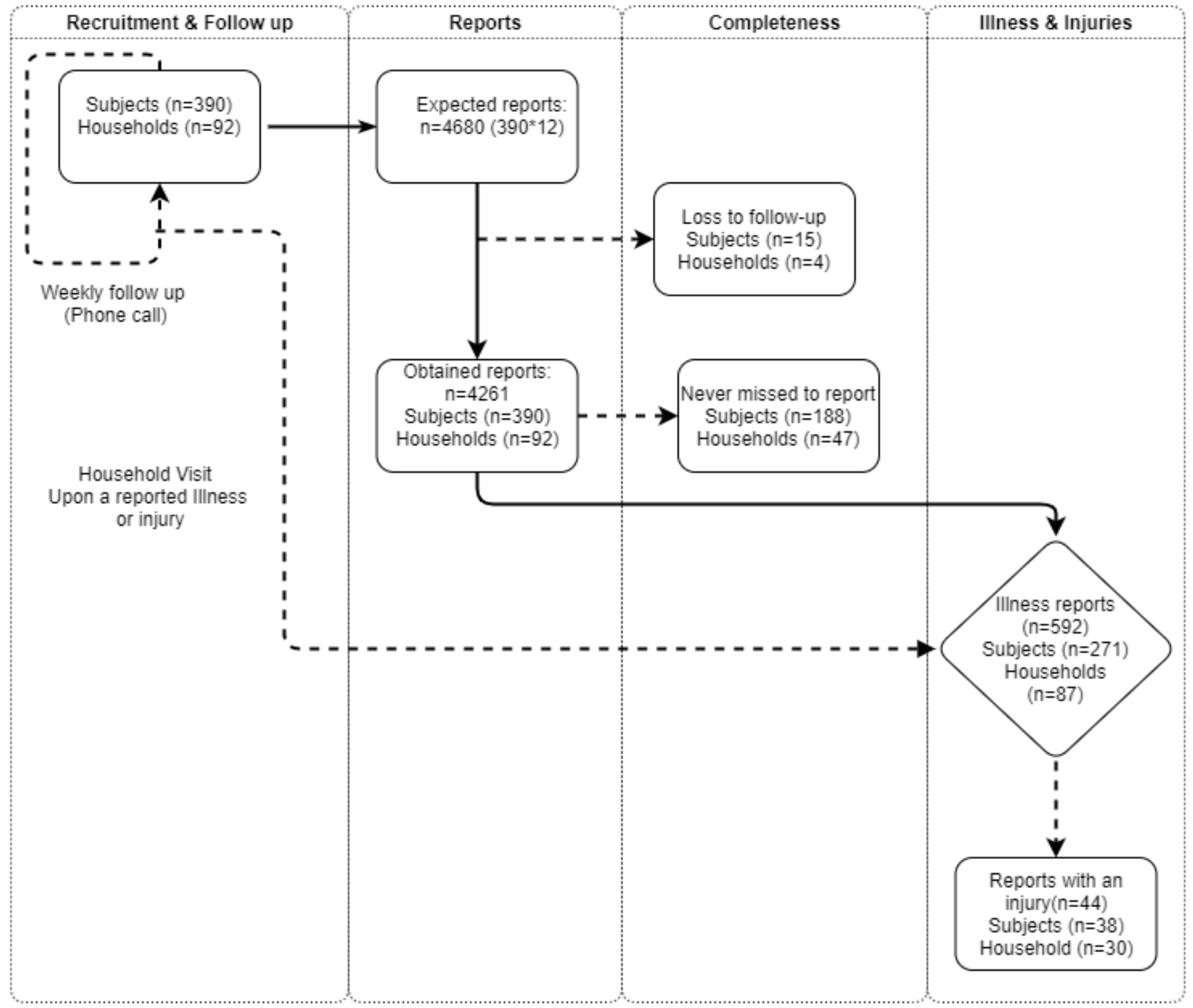

Figure 1 Schematic diagram showing the flow of the profile of the descriptive findings.

followed up 390 study subjects across the recruited 92 households weekly for 12 weeks. In total, we obtained 4261 reports covering August-October 2019 against the expected 4680 reports, yielding a response rate of $91 \%$ (figure 1). We consistently obtained reports in each week of follow-up without missing data from 188 (48\%) of the 390 study subjects (figure 1). These 188 study subjects were members of $47(51 \%)$ of the 92 study households. Only 15 study subjects distributed across four households were lost to follow-up due to other reasons including opting out of the study; however, they did not differ from those who remained in the study (figure 1).

The findings profile is summarised in a schematic diagram (figure 1).

\section{Longitudinal distribution of subjects reporting an injury}

Of the 4261 reports obtained, 592 (14\%) described an illness eligible to be investigated for injuries of which
$44(7.4 \%)$ documented an injury. Across time, injury frequencies overlapped between male and female subjects (figure 2).

In the 12 weeks of follow-up, the 44 reports came from 38 subjects constituting $10 \%$ of the entire 390 study subjects (figure 1). Of these 38 subjects, $55 \%$ were female. Additionally, of these 38 subjects, $34 \%$ belonged to the young age category, while $50 \%$ and $16 \%$ belonged to the middle and old age categories. Each of the 38 study subjects had, on average, 1.2 episodes of injuries across the 12 weeks of follow-up, yielding a mean of 17 injuries per 100 weeks (approximately 2 years).

\section{Demographic factors and nature of injuries}

The nature of injuries tallied in the 44 injury reports was $64 \%$ cuts and open wounds, $20 \%$ bruises and superficial injuries, $7 \%$ dislocations and 5\% animal bites, while we tallied burns and fractures in $2.3 \%$ of the reports, 


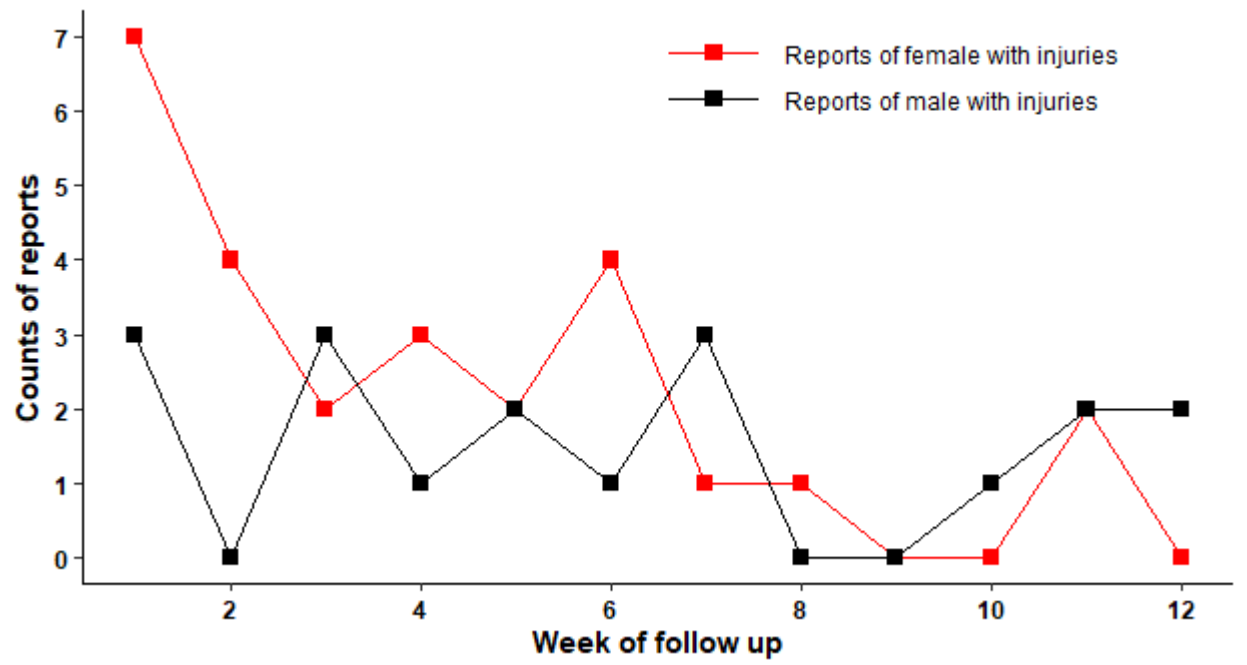

Figure 2 Longitudinal distribution of reports describing injuries.

respectively. Of the 44 reports, women (59\%) frequently reported injuries than men $(\mathrm{p}>0.05)$. On the other hand, the distribution of the 44 reports was $34 \%, 52 \%$ and $14 \%$ among young, middle-aged, and older subjects, respectively.

Table 3 shows the distribution of demographic factors and the nature of the injuries. While cuts and wounds were the most often reported among the middle-aged subjects, bruises were the most often reported among the young subjects (table 3 ).

\section{Cause of injuries and occupational factors}

Irrespective of age and gender, 30\%, 25\% and $23 \%$ of the 44 reports resulted from falls $(n=13)$, person-related assault or being hit by an object $(\mathrm{n}=11)$, and road accidents arising from vehicles or motorcycles $(n=10)$, respectively. The remaining 10 injuries were due to cuts from sharp objects, animal bites and fire burns (table 4).

Of the 44 reports of injuries, $18(41 \%)$ and $26(59 \%)$ reports came from school-going and non-school-going subjects, respectively. When classified by the most frequently reported injuries, falls $(n=13)$ were more likely $(62 \%)$ to be reported by school-going subjects. Personrelated assault or being hit by an object $(n=11)$ and road accidents $(\mathrm{n}=10)$ were $64 \%$ and $80 \%$ more likely to be reported by non-school-going subjects, respectively.

Multilevel univariable analyses of injuries

We used a multilevel univariable Poisson regression analysis factoring in the correlation of responses at individual and household levels. The analysis assessed the relationship between dichotomised reporting of an injury (yes vs no) and independent variables, returning three factors at $\mathrm{p}<0.1$. Of these three factors, visits outside the local subcounty of residence was the only factor at the subject level $(\mathrm{p}<0.001)$. The household-level factor included the keeping of a domestic animal $(\mathrm{p}=0.0081)$. Additionally, time in weeks treated as a risk factor predicted the occurrence of injuries $(p<0.001)$, while the area-level variable did not predict the occurrence (online supplemental table 1S).

\section{Multilevel multivariate Poisson regression model}

Adjusting for age and sex, the multilevel multivariate Poisson regression model factoring individual and household random effects returned three factors. These included making visits outside the local subcounty $(\mathrm{p}=0.007)$, domesticating an animal $(\mathrm{p}=0.020)$ and the

\begin{tabular}{|c|c|c|c|c|c|}
\hline Nature of injury & Age group (years) & Female (\%) & Male (\%) & Injury/1000 subjects/week & $95 \% \mathbf{C I}$ \\
\hline \multirow[t]{2}{*}{ Cuts, open wound } & $5-17$ & $4(14)$ & $5(18)$ & 17.0 & 16.4 to 49.3 \\
\hline & $>54$ & $1(4)$ & $1(4)$ & 3.8 & 3.6 to 10.9 \\
\hline \multirow{2}{*}{$\begin{array}{l}\text { Bruises, superficial } \\
\text { injury }\end{array}$} & $5-17$ & $1(11)$ & $3(33)$ & 7.6 & 7.3 to 21.8 \\
\hline & $>54$ & $2(22)$ & $0(0)$ & 3.8 & 3.6 to 10.9 \\
\hline
\end{tabular}

Other nature of injuries included dislocation, animal bites, fractures and burns, each having $\leq 3$ occurrences across age and gender. 
Table 4 Distribution and causes of injury by sex and age

\begin{tabular}{|c|c|c|c|c|c|}
\hline Cause of injury & Age group (years) & Female (\%) & Male (\%) & $\begin{array}{l}\text { Injury/1000 subjects/ } \\
\text { week }\end{array}$ & $95 \% \mathrm{Cl}$ \\
\hline \multirow[t]{2}{*}{ Falls } & $5-17$ & $4(31)$ & $4(31)$ & 15.2 & 14.6 to 43.8 \\
\hline & $>54$ & $2(15)$ & $0(0)$ & 3.8 & 3.6 to 10.9 \\
\hline $\begin{array}{l}\text { Person-related assault } \\
\text { or hit by an object }\end{array}$ & $5-17$ & $0(0)$ & $3(27)$ & 5.7 & 5.4 to 16.4 \\
\hline \multirow[t]{3}{*}{ Road accidents } & $5-17$ & $0(0)$ & $0(0)$ & 0.0 & 0.0 to 0.0 \\
\hline & $18-54$ & $6(60)$ & $4(40)$ & 18.9 & 18.3 to 54.8 \\
\hline & $>54$ & $0(0)$ & $0(0)$ & 0.0 & 0.0 to 0.0 \\
\hline
\end{tabular}

Other causes of injuries included cuts from sharp objects, animal bites, and fire burns each having $\leq 3$ occurrences across age and gender.

study week $(\mathrm{p}=0.038)$. The risk of reporting an injury decreased by $10 \%$ weekly. Subjects who made a visit outside the local subcounty were twofold higher at risk of reporting a physical injury at any study week compared with those who did not make a visit. Subjects not domesticating animals were eight times higher at risk of reporting injuries at any study week compared with those domesticating animals (table 5).

\section{DISCUSSION}

This study aimed to investigate factors associated with the weekly occurrence of physical injuries in a rural setting in Western Kenya. We determined the unique differences in nature, source and risks resulting from occupational, societal and demographic exposures associated with injuries. Injuries were more frequently reported by female subjects than male subjects, though the difference was non-significant. Moreover, the common causes of injuries among young, middle-aged and older subjects were falls, road accidents and person-related assault or being hit by an object, respectively. We classified these causes into occupational and societal risk exposures resulting from making visits outside the local subcounty and not owning a domestic animal that independently predicted the occurrence of injuries.

Injuries were more often reported by middle-aged subjects relative to other age groups, suggesting agerelated differential exposures. Previous studies disproportionately link high injury frequencies among adults and communities with low education and poverty levels similar to our setting. ${ }^{24}{ }^{25}$ Indeed, the majority $(70 \%)$ of the middle-aged subjects reporting injuries had primary or no education, earning a low monthly income of $>10000$ Kenya shillings ( $\sim$ US $\$ 100$ ). The more frequent reports from female subjects that we found contrasted with findings from a cross-sectional study conducted

\begin{tabular}{lllll}
\hline \multicolumn{4}{l}{ Table 5} & Random-intercept Poisson regression model analysis for injuries \\
\hline Variable & Levels & IRR & IRR (95\% Cl) & P value \\
\hline Week & & 0.90 & 0.82 to 0.99 & 0.038 \\
Visits outside & Yes & 2.16 & 1.54 to 3.11 & 0.007 \\
& No & Reference & - & \\
Domesticate animals & Yes & Reference & - & \\
& No & 7.59 & 1.38 to 41.7 & 0.020 \\
Gender & Male & 0.87 & 0.37 to 2.04 & 0.748 \\
& Female & Reference. & - & \\
Age & & 1.00 & 0.99 to 1.03 & 0.454
\end{tabular}

Random parameter

\begin{tabular}{lll} 
Variance & Household (level 3) & 0.63 \\
Study participant (level 2) & 4.05 \\
Residual (level 1) & 8.28 \\
\hline
\end{tabular}

Akaike information criterion 464.9, Bayesian information criterion 515.8, log likelihood -224.5, deviance 448.9.

IRR, incident rate ratio. 
elsewhere in Kenya, ${ }^{26}$ perhaps due to more women taking up more strenuous roles in male-dominated sectors. ${ }^{27}$ This finding suggested varied risk exposures between gender and their physical or social environments. People with low levels of education especially in rural settings are more likely to engage in occupations with elevated risks for injuries. Hence, there is a need for targeted public health interventions to promote home and occupational safety in rural areas. ${ }^{25}$

We documented a fairly small number of 0.21 injuries weekly from $34 \%$ of the 87 study households that reported an illness, with the majority $(61 \%)$ of such injuries resulting from falls and person-related assault or being hit by an object. While injuries due to personrelated assault could have resulted from violence or abuse, among other causes that this study did not focus on, those from falls resulted from essential daily activities including household chores, farming and schooling among others, which could have potentially advanced the risk of physical injuries. Indeed, although earlier studies associate the essential daily activities and occupations with the occurrence of unintentional injuries and physical violence or abuse with intentional injuries across all age groups, gaps still exist in their documentation and subsequent social or economic impacts in rural settings. ${ }^{28}$ Nonetheless, preventable injuries could be overcome by investing in home or occupational safety in rural areas. ${ }^{29}$

Subjects not domesticating animals were eight times at higher risk of reporting injuries compared with those domesticating animals. Indeed, those domesticating animals were likely to use them, particularly cattle, for draught power compared with those not domesticating and therefore likely to use risky hand tools or outdated machinery during farming or in any other activities. Such tools and machines increased the likelihood of injuries, as also identified in cross-sectional studies conducted in Nepal and Ethiopia. ${ }^{30}{ }^{31}$ On the other hand, the reduced risk $(1 / 8)$ of reporting injuries among subjects domesticating animals signals the minimal exposure to injuryprone inanimate machines or tools in livestock farming or transportation. Nevertheless, there is still a need to create awareness on occupational safe handling of domestic animals. $^{32} 33$

Under the societal exposure of injuries, subjects making visits outside the subcounty of residence were at twofold higher risk of reporting injuries perhaps due to increased use of motorcycles as a mode of transport. ${ }^{345}$ Motorcycles are beginning to be a frequent cause of injuries in Kenya, arising from crashes due to varied factors. ${ }^{36}$ Indeed, all motorcycle-related and vehicle-related injuries were most frequent among subjects aged between 18 and 54 years compared with other age categories since this group is generally more active and productive while seeking livelihoods. Previous studies associate adults aged above $>18$ years with risky behaviours such as drunk riding, failing to wear a helmet while riding, riding with excess passengers and speeding among others. ${ }^{36}{ }^{37}$ For these reasons, road safety interventions including enforcement of mandatory use of helmets, driver training and age-restricted motorcycle ownership and licensure could be instituted to reduce related injuries in similar rural settings. ${ }^{38}$

\section{CONCLUSION}

The study established the existence of occurrences of physical injuries in a rural setting. Subjects who made a visit outside the subcounty of residence were more likely to report injuries relative to those who did not. Further, subjects not domesticating animals were more likely to report injuries relative to those domesticating animals. These findings suggest that tackling increasing risk exposures in rural western Kenya using targeted public health interventions could effectively reduce injuries across all age groups.

Acknowledgements We acknowledge Duncan Ogutu and Phillip Misiani for their support in the community and the participation of study participants in this study.

Contributors RNC, SNM and JMG conceived and designed the study protocol. RNC and JMG contributed significantly to the recruitment and data collection processes. Data analysis was planned by RNC and JMG, with the analysis performed by RNC and the reviewed by JMG. All authors contributed significantly to developing the manuscript.

Funding The authors have not declared a specific grant for this research from any funding agency in the public, commercial or not-for-profit sectors.

Map disclaimer The inclusion of any map (including the depiction of any boundaries therein), or of any geographic or locational reference, does not imply the expression of any opinion whatsoever on the part of BMJ concerning the legal status of any country, territory, jurisdiction or area or of its authorities. Any such expression remains solely that of the relevant source and is not endorsed by BMJ. Maps are provided without any warranty of any kind, either express or implied.

Competing interests None declared.

Patient consent for publication Not required.

Ethics approval We sought ethical clearance for this study from AMREF Health Africa Ethics and Scientific Review Committee, approved under application number P635/2019.

Provenance and peer review Not commissioned; externally peer reviewed.

Data availability statement All data relevant to the study are included in the article or uploaded as supplementary information.

Supplemental material This content has been supplied by the author(s). It has not been vetted by BMJ Publishing Group Limited (BMJ) and may not have been peer-reviewed. Any opinions or recommendations discussed are solely those of the author(s) and are not endorsed by BMJ. BMJ disclaims all liability and responsibility arising from any reliance placed on the content. Where the content includes any translated material, BMJ does not warrant the accuracy and reliability of the translations (including but not limited to local regulations, clinical guidelines, terminology, drug names and drug dosages), and is not responsible for any error and/or omissions arising from translation and adaptation or otherwise.

Open access This is an open access article distributed in accordance with the Creative Commons Attribution Non Commercial (CC BY-NC 4.0) license, which permits others to distribute, remix, adapt, build upon this work non-commercially, and license their derivative works on different terms, provided the original work is properly cited, appropriate credit is given, any changes made indicated, and the use is non-commercial. See: http://creativecommons.org/licenses/by-nc/4.0/.

\section{ORCID iDs}

Reagan Ngoge Chweya http://orcid.org/0000-0003-3043-5817 John Mwangi Gachohi http://orcid.org/0000-0001-9854-7490 


\section{REFERENCES}

1 Diamond MB, Dalal S, Adebamowo C, et al. Prevalence and risk factor for injury in sub-Saharan Africa: a multicountry study. Inj Prev 2018;24:272-8.

2 Onywera VO, Blanchard C. Road accidents: a third burden of 'disease' in sub-Saharan Africa. Glob Health Promot 2013;20:52-5.

3 Garcia PJ. Global burden of injuries: it is time to understand the data in order to intervene. Inj Prev 2020;26:11-2.

4 Pant PRet al. Burden of injuries in Nepal, 1990-2017: findings from the global burden of disease study 2017. Inj Prev 2019;0:1-10.

5 Bhalla K, Harrison J, Abraham J, et al. Data sources for improving estimates of the global burden of injuries: call for contributors. PLoS Med 2009;6:e1000001.

6 Gathecha GKet al. Prevalence and predictors of injuries in Kenya: findings from the National steps survey 11 medical and health sciences 1117 public health and health services. BMC Public Health 2018;18:1222.

7 Gathecha GK, Githinji WM, Maina AK. Demographic profile and pattern of fatal injuries in Nairobi, Kenya, January-June 2014. BMC Public Health 2017;17:1-7.

8 Bachani AM, Taber N, Mehmood A, et al. Adolescent and young adult injuries in developing economies: a comparative analysis from Oman and Kenya. Ann Glob Heal 2017;83:791-802.

9 Janeway H, O'Reilly G, Schmachtenberg F, et al. Characterizing injury at a tertiary referral hospital in Kenya. PLoS One 2019;14:e0220179.

10 Botchey IM, Hung YW, Bachani AM, et al. Epidemiology and outcomes of injuries in Kenya: a multisite surveillance study. Surgery 2017;162:S45-53.

11 James SL, Castle CD, Dingels ZV, et al. Global injury morbidity and mortality from 1990 to 2017: results from the global burden of disease study 2017. Inj Prev 2020;26:i96-114.

12 Chweya RN, Mambo SN, Gachohi JM. The occurrence of selfreported illnesses and their analyses into influenza-like and gastrointestinal syndromes in a rural community in Western Kenya, 2019. Int. J. Community Med. Public Heal 2021;8:1-9.

13 Chweya RN, Mambo SN, Gachohi JM. Longitudinal analyses suggest a higher burden of self-reported influenza-like illness among women and girls in a rural community in Western Kenya. Global Epidemiology 2018.

14 UNICEF. Designing and selecting the sample, 2005. Available: http:// mics.unicef.org/files?job=W1 siZilsljlwMTUvMDQvMDIvMDgvMDAv MTkvODEwL01JQ1MzXONoYXB0ZXJfNF9fXORlc2InbmluZ19hbmRf U2VsZWN0aW5nX3RoZV9TYW1wbGVfMDYwMjE5LnBkZiJdXQ\& sha $=3 \mathrm{~d} 97 \mathrm{a} 05358 \mathrm{bb0e37}$

15 Kasiulevicius V, apoka V, Filipaviciute R. Sample size calculation in epidemiological studies. Gerontologija 2006;7:225-31.

16 Lai MHC, Kwok OM. Examining the rule of thumb of not using multilevel modeling: the "design effect smaller than two" rule. $J$ Exp Educat 2015;83:423-38.

17 KNBS. Distribution of population by administrative units. 2019 Kenya population and housing census 2019.

18 Hartung C. Open data kit: tools to build information services for developing regions, 2010.

19 R Core Team. R: a language and environment for statistical computing, 2019. Available: https://www.r-project.org/
20 Jacquez GM. A K nearest neighbour test for space-time interaction. Stat Med 1996;15:1935-49.

21 Wilson R, Din A. Calculating varying scales of clustering among locations. Cityscape 2018;20.

22 Sethi D. Guidelines for conducting community surveys on injuries and violence, 2004. Available: www.inis.ie

23 Vincent Dorie Aet al. Package 'blme' title bayesian linear mixedeffects models description maximum a posteriori estimation for linear and generalized linear mixed-effects models in a Bayesian setting. Extends 'Ime4' by 2016.

24 Gielen AC, McDonald EM, Shields W. Unintentional home injuries across the life span: problems and solutions. Annu Rev Public Health 2015;36:231-53.

25 Ferrante P, Marinaccio A, lavicoli S. Home injuries in Italy: patterns of injury and the most exposed people. Int $J$ Inj Contr Saf Promot 2013;20:36-41.

26 Gathecha GK, Ngaruiya C, Mwai W, et al. Prevalence and predictors of injuries in Kenya: findings from the National steps survey. BMC Public Health 2018;18:1222.

27 Abdalla S, Apramian SS, Cantley LF. Occupation and risk for injuries. In: Disease control priorities. 3rd edn. Injury Prevention and Environmental Health, 2017: 97-132.

28 Odero W, Polsky S, Urbane D, et al. Characteristics of injuries presenting to a rural health centre in Western Kenya. East Afr Med J 2007;84:367-73.

29 El Tayeb S, Abdalla S, Mørkve O, et al. Injuries in Khartoum state, the Sudan: a household survey of incidence and risk factors. Int $J$ Inj Contr Saf Promot 2014;21:144-53.

30 Yiha O, Kumie A. Assessment of occupational injuries in tendaho agricultural development S.C, afar regional state. Ethiop J Heal Dev 2010;24:167-74.

31 Bhattarai D, Singh SB, Baral D, et al. Work-Related injuries among farmers: a cross-sectional study from rural Nepal. J Occup Med Toxicol 2016;11:1-7.

32 Langley RL. Animal-related fatalities in the United States-an update. Wilderness Environ Med 2005;16:67-74.

33 Weaver JL, Kimbrough CW, Broughton-Miller K, et al. Danger on the farm: a comparison of agricultural and Animal-Related injuries. Am Surg 2017;83:507-11.

34 Lin M-R, Chang S-H, Huang W, et al. Factors associated with severity of motorcycle injuries among young adult riders. Ann Emerg Med 2003;41:783-91.

35 Solagberu BA, Ofoegbu CKP, Nasir AA, et al. Motorcycle injuries in a developing country and the vulnerability of riders, passengers, and pedestrians. Inj Prev 2006;12:266-8.

36 Ngari PM, Gachohi J, Ngure PK. Prevalence and factors associated with commercial motorcycle accidents in embu County, Kenya. $J$ Health Med Nurs 2020;5 www.iprjb.org

37 Al-Aamri AK, Padmadas SS, Zhang L-C, et al. Disentangling agegender interactions associated with risks of fatal and non-fatal road traffic injuries in the Sultanate of Oman. BMJ Glob Health 2017;2:e00 0394:e000394.

38 Lin M-R, Kraus JF. A review of risk factors and patterns of motorcycle injuries. Accid Anal Prev 2009;41:710-22. 